\title{
Diversity, spatial distribution and activity of fungi in freshwater ecosystems
}

\author{
Cécile Lepère ${ }^{\text {Corresp.. }}{ }^{1}$ ， Isabelle Domaizon ${ }^{2}$, Jean-Francois Humbert ${ }^{3}$ ， Ludwig Jardillier ${ }^{4}$, Mylène Hugoni ${ }^{5}$, \\ Didier Debroas ${ }^{1}$ \\ 1 Laboratoire: Microorganismes: Génome et Environnement, Université Clermont Auvergne, Clermont-Ferrand, France \\ 2 CARRTEL, Université Savoie Mont Blanc, INRA, Thonon Les Bains, France \\ 3 iEES Paris, Sorbonne Université, INRA, Paris, France \\ 4 Unité d'Ecologie, Systématique et Evolution, Univ. Paris-Sud, CNRS, AgroParisTech, Université Paris-Saclay, Université Paris Sud (Paris XI), Orsay, France \\ 5 CNRS, UMR5557, Ecologie Microbienne, INRA, UMR1418, Université Lyon 1, Villeurbanne, France \\ Corresponding Author: Cécile Lepère \\ Email address: cecile.lepere@uca.fr
}

High-throughput sequencing has given new insights into aquatic fungal community ecology over the last 10 years. Based on 18S ribosomal RNA gene sequences publicly available, we investigated fungal richness and taxonomic composition among 25 lakes and 4 rivers. We used a single pipeline to process the reads from raw data to the taxonomic affiliation. In addition, we studied, for a subset of lakes, the active fraction of fungi through the $18 \mathrm{~S}$ rRNA transcripts level. These results revealed a high diversity of fungi that can be captured by $18 \mathrm{~S}$ rRNA primers. The most OTU-rich groups were Dikarya (47\%), represented by putative filamentous fungi more diverse and abundant in freshwater habitats than previous studies have suggested, followed by Cryptomycota (17.6\%) and Chytridiomycota (15.4\%). The active fraction of the community showed the same dominant groups as those observed at the 18S rRNA genes level. On average $13.25 \%$ of the fungal OTUs were active. The small number of OTUs shared among aquatic ecosystems may result from the low abundances of those microorganisms and/or they constitute allochthonous fungi coming from other habitats (e.g. sediment or catchment areas). The richness estimates suggest that fungi have been overlooked and undersampled in freshwater ecosystems, especially rivers, though they play key roles in ecosystem functioning as saprophytes and parasites. 
2 Cécile Lepère ${ }^{*}$, Isabelle Domaizon ${ }^{2}$, Jean-Francois Humbert ${ }^{3}$, Ludwig Jardillier ${ }^{4}$, Mylène 3 Hugoni $^{5}$ and Didier Debroas ${ }^{1}$.

4 'Université Clermont Auvergne, CNRS, Laboratoire: Microorganismes: Génome et

5 Environnement, Clermont-Ferrand, France

$6 \quad$ 2INRA, CARRTEL, Université Savoie Mont Blanc, Thonon Les Bains, France,

7 3INRA, iEES Paris, Sorbonne Université, Paris, France

8 'Unité d'Ecologie, Systématique et Evolution, Univ. Paris-Sud, CNRS, AgroParisTech, 9 Université Paris-Saclay, Orsay, France

105 Université Lyon 1 - CNRS, UMR5557, Ecologie Microbienne, INRA, UMR1418, 11 Villeurbanne, France

12 *Corresponding author: Cécile Lepère, Université Clermont Auvergne, CNRS, Laboratoire: 13 Microorganismes: Génome et Environnement, Clermont-Ferrand, France. E-mail: 14 cecile.lepere@uca.fr

\section{SUMMARY}

18 High-throughput sequencing has given new insights into aquatic fungal community ecology over 19 the last 10 years. Based on 18S ribosomal RNA gene sequences publicly available, we 20 investigated fungal richness and taxonomic composition among 25 lakes and 4 rivers. We used a 21 single pipeline to process the reads from raw data to the taxonomic affiliation. In addition, we 22 studied, for a subset of lakes, the active fraction of fungi through the 18S rRNA transcripts level. 23 These results revealed a high diversity of fungi that can be captured by $18 \mathrm{~S}$ rRNA primers. The 24 most OTU-rich groups were Dikarya (47\%), represented by putative filamentous fungi more 25 diverse and abundant in freshwater habitats than previous studies have suggested, followed by 26 Cryptomycota $(17.6 \%)$ and Chytridiomycota $(15.4 \%)$. The active fraction of the community 
27 showed the same dominant groups as those observed at the 18S rRNA genes level. On average $2813.25 \%$ of the fungal OTUs were active. The small number of OTUs shared among aquatic ecosystems may result from the low abundances of those microorganisms and/or they constitute allochthonous fungi coming from other habitats (e.g. sediment or catchment areas). The richness estimates suggest that fungi have been overlooked and undersampled in freshwater ecosystems, especially rivers, though they play key roles in ecosystem functioning as saprophytes and parasites.

\section{INTRODUCTION}

Molecular diversity of microbial eukaryotes in aquatic ecosystems is far less investigated than their prokaryotic counterparts. This is even more striking for particular groups such as fungi that attract very little interest. This bias partly results from their supposed low abundances (e.g. $~ 1 \%$ of total marine eukaryotes (Massana and Pedros-Alio, 2008)) that suggests fungi have little ecological importance in aquatic ecosystems. However, rare organisms can play crucial roles in ecosystem functioning but more importantly recent studies have revealed much bigger proportions of fungi than previously observed, as well as high taxonomic richness in different marine (Le Calvez et al. 2009; Gao et al. 2010; Orsi et al. 2013; Richards et al. 2012; Lepère et al. 2015) and freshwaters environments (Monchy et al. 2011; Ishii et al. 2015; Duarte et al. 2015; Lepère et al. 2016). The extent of fungal biodiversity is therefore likely underestimated (Scheffers et al. 2012) though diversity estimates based on molecular data suggest that it can range between 0.5 and 10 million species (Hawksworth, 2001; O’Brien et al., 2005; Mora et al. 2011; Bass and Richards, 2011; Blackwell, 2011).

Despite this putative rich biodiversity, functional roles of aquatic fungi, for which only 3,0004,000 species have been recorded, remain poorly characterized (Pautasso, 2013; Rambold et al., 2013). They are mainly known as decomposers of leaves in rivers, mangroves and wetlands (Seena et al. 2008; Gulis et al. 2008) and as parasites of phytoplankton and zooplankton in lake ecosystems (Jobard et al. 2010). A decade ago, fungi were divided into four main phyla: Basidiomycota, Ascomycota, Zygomycota and Chytridiomycota (James et al. 2006). However, phylogeny of fungi is still unresolved and several phyla, classes and orders of basal fungi have 
56 been determined, since. For example, Corradi et al. (2015) highlighted that Cryptomycota forms

57 a new phylum in which we can find Mirosporodia, Aphelids and Rozellids. The vast majority of 58 this phylum is characterized by environmental sequences and gathered under the term "dark 59 matter fungi" (Grossart et al., 2015). These fungi are mostly zoosporic and "old" in term of 60 evolution since they diverged from the remaining fungi 710-1060 million years ago (Lücking et 61 al., 2009). These basal fungi are distant from cultured and described fungi. Aquatic environments 62 are thus likely to host a high number of uncharacterized groups (Grossart et al. 2016).

63 With the goal to draw up an inventory of existing knowledge on the diversity, distribution and 64 ecology of aquatic fungi, we (1) combined all publicly available fungal $18 \mathrm{~S}$ ribosomal RNA 65 gene sequences produced by high-throughput sequencing approach from freshwater studies (2) 66 compared fungal composition across environments (3) analysed a new set of data presenting $18 \mathrm{~S}$ 67 rRNA transcripts abundance on a sub-sample of 8 lakes in order to characterize the active part of 68 the community. 
72

73

74 75 76 77 78 79 80 81 82

\section{MATERIALS AND METHODS}

\section{Data collection of $18 S$ rRNA genes in public databases}

In this work, we collected a set of publically available data that were related to HTS (pyrosequencing and Illumina with MiSeq technology) of the V4 region of the gene encoding for 18S rRNA (Table 1, Sup Table 2 and Debroas et al. (2017)). These sequences were obtained from freshwater ecosystems (25 lakes and ponds, and four rivers), sampled at various depths and dates (long term or periodically), and/or obtained from various size fractions (Table 1).

In this analysis, we included external references such as V4 amplicons sequenced from a few non-freshwater ecosystems (marine ecosystems and environments characterized by salinity gradients) to compare environments and define spurious OTUs (i.e., singletons, see below) (Table 1).

\section{RNA extraction and $18 S$ rRNA amplification}

To go further than the analysis of $18 \mathrm{~S}$ rRNA genes we sampled eight lakes which are included in the meta-analysis (Vichy, Aydat, Cournon, Grangent, Roche aux Moines, Eguzon, Fades and Pavin, table 1) to studied the $18 \mathrm{~S}$ rRNA transcript level. They included both natural and humanmade waterbodies with considerable heterogeneity in terms of surface area and catchment characteristics. Sampling was carried out during the homothermy period in winter 2013-2014 as described in Hugoni et al. (2015). Water samples were integrated in the photic zone of each lake over the deepest part of the lake. A sub-sample of water $(300 \mathrm{~mL})$ was pre-filtered through 150 and $50-\mu \mathrm{m}$ pore-size filters and collected on $0.2-\mu \mathrm{m}$ pore-size (pressure $<10 \mathrm{kPa}$ ) polycarbonate filters (Millipore) before storage at $-80^{\circ} \mathrm{C}$ until nucleic acid extraction.

The nucleic acids extraction method was done as described in Hugoni et al. (2015). Briefly, after thermic and enzymatic cell lysis, the AllPrep DNA/RNA kit (Qiagen, Valencia, CA) was used. RNA samples were tested for the presence of contaminating genomic DNA using PCR and then reverse transcribed with random primers using SuperScript ${ }^{\circledR}$ VILO (Invitrogen). Amplification of the V4 region of the 18S rRNA genes among cDNA was performed using the universal primer 515F (GTG-YCA-GCM-GCC-GCG-GTA, Caporaso, 2010) and the eukaryotic primer 951R (TTG-GYR-AAT-GCT-TTC-GC). Sequencing was achieved by the Genoscreen platform (Lille, France), using an Illumina Miseq paired-end chemistry. 
Sequence analysis procedures

103 All sequence data (public databases and new data) were examined against the following quality 104 criteria: For the pyrosequencing data: (i) no Ns in the nucleotide sequence, (ii) quality score $\geq 23$ 105 according to the PANGEA process (Giongo et al., 2010), (iii) a minimum sequence length of 200 $106 \mathrm{bp}$, and (iv) no sequencing errors in the forward primer. The MiSEQ data were assembled with 107 the USEARCH tool (usearch v7.0.1090_i86linux64)(Edgar, 2013) and examined in relation to 108 the previous criteria as well as for the absence of errors in the reverse primer. Putative chimeras 109 and homopolymers were detected by UCHIME (Edgar et al., 2011) and the script 110 homopolymer_count.pl(http://alrlab.research.pdx.edu/aquificales/pyrosequencing.html).

111 The clean-freshwater reads were clustered at a 95\% similarity threshold (Mangot et al. 2013;

112 Lepère et al. 2016; Debroas et al. 2017) with USEARCH 7.0 (option: cluster_fast) (Edgar, 2013)

113 to identify representative OTUs. Clean data for the external references (e.g. sequences from 114 organisms in marine environments) and selected sequences from the SILVA database named 115 RefEUKs (Debroas et al. 2017) were mapped on the representative OTUs to define them. This 116 procedure allowed us to remove the singletons. A singleton in freshwater environments was 117 therefore defined as a read sequenced only once, regardless of the environment, and that was 118 absent in the SILVA database.

\section{Taxonomic affiliations}

121 The representative OTUs were affiliated by similarity and phylogeny with a curated reference 122 sequences named RefEUKs (https://github.com/panammeb/). These eukaryote references were 123 extracted from the SSURef SILVA database (Pruesse et al., 2007) according to the following 124 criteria: length $>1200 \mathrm{bp}$, alignment quality score $>75 \%$, and a pintail value $>50$. In addition, 125 the taxonomy of this reference database was modified to include typical freshwater lineages (e.g. 126 fungi) defined in previous studies (e.g., Debroas et al. 2015). After a comparison of the OTUs 127 with the RefEUKs by a similarity approach (USEARCH tool), trees of OTUs with their closest 128 reference sequences were built in FastTree (Price et al. 2010) (see Debroas et al. 2017 for 129 detailed pipeline). Taxonomic assignment was conducted according to two methods: nearest 130 neighbour (NN), and last common ancestor (LCA) affiliations (Liu et al. 2008). 
132 Comparing representative OTUs with reference sequences from a public database

133 To compare freshwater OTUs to reference 18S rRNA gene sequences found in the public 134 database, we used two criteria: similarity and phylogenetic metrics. In the first approach, OTUs 135 were compared to the SSURef SILVA database and were restricted to the total or cultivated 136 eukaryotes using BLAST. In the second, different phylogenetic indices (Swenson, 2009) were 137 computed from the trees generated in the pipeline described above. The "X depth/deeper" is 138 defined as the average distance to the deepest node in the tree (Pommier et al. 2009). These 139 various indices were computed using R software with the packages "picante" (Kembel et al. 140 2010), "Geiger," and "ape" (Paradis et al. 2004), and were implemented in PANAM (Taib et al. 141 2013).

143 Statistics

144 Different estimators were used to infer the taxa richness of the planktonic eukaryotes: non145 parametric estimators (Chao1, ACE) and indices based on the rank-abundance curves. These 146 estimators were computed with Vegan (Dixon, 2003) and "species" packages implemented in R.

\section{TSA-FISH (Tyramide Signal Amplification-Fluorescent In situ Hybridization)}

149 On two lakes (Aydat, Pavin) included in the meta-analysis we performed TSA-FISH to detect 150 Cryptomycota. The probe used was the LKM11-01 (Mangot et al. 2009) and the protocole is 151 described in Lepère et al. (2016).

\section{RESULTS}

154 Richness and community composition of freshwater fungi

155 The rarefaction curves built from OTUs show that a plateau is reached for lakes and for 156 freshwater environments considered as a whole (lakes + rivers). On average 37680 reads per 157 samples were obtained. No plateau is obtained for river ecosystems (Figure 1). From 1.6 million 158 of reads, our analysis recovered 19,008 fungal OTUs at a similarity threshold of 95\% (Debroas et 
159 al. 2017). The estimated OTU richness in rivers, lakes and freshwater ecosystems (lakes + rivers)

160 vary according to the estimators (Table 2). The majority of the fungi retrieved in freshwater are 161 represented by Dikarya (Ascomycota and Basidiomycota), Cryptomycota and Chytridiomycota.

162 All estimators suggest that Cryptomycota is the richest group in both lakes and rivers while the 163 lowest richness is found for the Basidiomycota in lakes and Ascomycota in rivers (Table 2). 164

165 When looking at the OTU taxonomic level in freshwater (lakes + rivers), 47\% of fungal OTUs 166 (26\% of reads) are affiliated to Dikarya (1/3 to Basidiomycota, 2/3 to Ascomycota) followed by 167 basal fungi: Cryptomycota (17.6\% OTUs; 15\% reads) and Chytridiomycota (15.4\% OTUs; 12\% 168 reads) (Figure 2). Moreover, 16\% of the OTUs can't be affiliated and are grouped under 169 "unclassified fungi". These "unclassified fungi" represent 50\% of the reads (Figure 2). Most of 170 the OTUs with a taxonomic affiliation belonged to the subkingdom Dikarya (Ascomycota, 171 Basidiomycota) in both lakes and rivers. The majority (almost 85\%) of Ascomycota OTUs group 172 within the Pezizomycotina (Sup Figure 1) and the most represented class within this subphylum 173 is the Dothideomycetes. The rest of the Ascomycota OTUs belong to Ascomycota yeasts 174 (subphylum: Saccharomycotina subphylum, class: Saccharomycetes).

175 A high proportion of Basidiomycota sequences are also found in our dataset, with the majority 176 being yeast fungi. The three major clades of Basidiomycota are represented: Agaricomycotina, 177 Pucciniomycotina and Ustilaginomycotina with the Agaricomycotina accounting for 53\% of the 178 Basidiomycota OTUs (Sup Figure 1).

Spatial distribution of freshwater fungi

181

182 All phyla were detected in lakes and rivers but several are found at very low proportion, less than 183 $1 \%$ of the OTUs and less than $2 \%$ of the reads (i.e. Blastocladiomycota, Glomeromycota). At a 184 finer taxonomic resolution (i.e. OTUs level), 3,369 OTUs (18\%) are found in both lakes and 185 rivers while $12,424(66 \%)$ are restricted to lakes and 3,215 to rivers (16\%) (Sup Figure 2). 186 Regarding the basal fungi, Cryptomycota OTUs predominate over Chytridiomycota in river 187 while OTUs belonging to Chytridiomycota are more abundant in lakes as well as the proportion 188 of Dikarya (Sup Figure 3). When considering only lacustrine ecosystems, the number of OTUs 189 shared by the different lakes decrease exponentially with the number of lakes leading to the fact 
190 that $61 \%$ of the OTUs (9642) are restricted to one lake only. No OTU is shared by more than 19

191 lakes (over the 25 considered) and only $0.2 \%$ of the OTUs are shared by more than twelve lakes.

192 There is a link between the most ubiquitous taxa and their abundances (i.e. number of reads),

193 with the most widely distributed falling within the most abundant OTUs (Figure 3). The top 10

194 most abundant OTUs (representing 7334 reads per lake on average) are shared by a minimum of

1958 lakes (Figure 3). However, there is no linear relationship between abundance and distribution.

196 For example, one Cryptomycota OTU (Leman_S2331067) belongs to the 32 more abundant

197 OTUs though it is detected in one lake only. The most shared OTUs between lakes belong to

198 Chytrids and Dikarya while the more abundant belong to Basidiomycota and Cryptomycota

199 (Figure 3).

200789 fungal OTUs detected in freshwater are also found in marine environments displaying 201 different salinities (Table Sup 1). The majority of these OTUs (582) are detected in lakes. Most

202 of the OTUs (224) shared by marine environments and lakes belong to Ascomycota and Chytrids

203 (145). Rivers and marine environments share a majority of Ascomycota (82) and Cryptomycota

204 (44) OTUs (Sup Figure 2).

205

206

\section{Active fungi in freshwater lakes}

207 By targeting the 18S rRNA transcripts on a reduced number of lakes found in this meta-analysis 208 (Vichy, Aydat, Cournon, Grangent, Roche Moines, Eguzon, Fades and Pavin, table 1), we found 209 that $30 \%$ of the eukaryotes OTUs are represented by fungi while they represent only $7,2 \%$ of the

210 reads. 18S rRNA transcript sequencing showed the same dominant phylogenetic groups assessed

211 by $18 \mathrm{~S}$ rRNA genes analysis: Dikarya, Cryptomycota, Chytridiomycota as well as a large

212 proportion of unclassified sequences. The mean rRNA transcripts: rRNA genes ratio computed

213 from each OTU is 0,82. On average 13.25\% of the fungal OTUs were active (Figure 4a) (i.e.,

214 rRNA:rDNA ratio > 1). If we focus on the Dikarya which includes a broad diversity, some

215 subphyla were more active than the others. Within the Basidiomycota, the Ustilaginomycotina

216 did not seem to be active (Figure $4 \mathrm{~b}$ ) whereas 28\% of the Agaricomycotina were active (Figure

217 4b). The most active subphylum within the Ascomycota is the Pezizomycotina (Figure 4b) and

218 the number of sequences in the $18 \mathrm{~S}$ rRNA transcripts dataset was more abundant than in the $18 \mathrm{~S}$

219 rRNA genes dataset also for Saccharomycotina and Mitosporic Ascomycota while the 
environmental sequences showed the opposite.

\section{DISCUSSION}

222

223

224

225

226

227

228

229

230

231

232

233

234

235

236

237

238

239

240

241

242

243

244

245

246

247

248

249

\section{$18 S$ rRNA gene sequences}

Until recently, fungi were one of the most understudied microbial groups in aquatic ecosystems, being more studied in terrestrial habitats. This trend has changed over the last decade and there is now more interest in deciphering the diversity and role played by fungal communities in aquatic ecosystems. Aquatic fungi have been studied through environmental clone library approaches (Lai et al. 2007) or high-throughput sequencing (HTS) using specific fungal primers (Monchy et al. 2011; Arfi et al. 2012; Wang et al. 2014; Duarte et al. 2015; Zhang et al. 2016). However, aquatic fungi are most often not considered on their own but rather studied as part of studies investigating whole microbial eukaryotic communities (Livermore and mattes, 2013; Panzer et al. 2015; Hassett and Gradinger, 2016; Tisthammer et al. 2016). Therefore, the majority of the data available on aquatic fungi is 18S rRNA gene sequences. Recently, Philippis et al. (2017) showed that $18 \mathrm{~S}$ rRNA gene allow a more reliable quantification of fungi than the ITS region. ITS, which is the most accurate phylogenetic marker for fungi based on in silico simulations, promotes preferential amplification of shorter sequences and therefore leads to a biased view of taxa relative abundance. In freshwaters, the main phylogenetic markers used are the V4 (Table 1) and V9 regions (Korajkic et al., 2015) of the 18S rRNA and, more rarely, the V3 zone (Nolte et al., 2010). For an easier and more accurate taxonomic identification, we choose to focus on the V4 sequences since this is the largest dataset but also because this variable zone is present in almost all Sanger sequences deposited in GenBank. The sequences analyzed in this study have been obtained by the use of five "universal" primer sets which could introduce biases in the meta-analysis. Indeed, even if these primer sets target a similar V4 region of the 18S rDNA, they may lead to slightly different taxonomic compositions (Debroas et al. 2017). Moreover the different DNA extraction methods used in the studies considered in this analysis may produce bias. Indeed, the accuracy of the data depends on how well the DNA is extracted from the environment, so that it accurately reflects the composition of the actual microbial community (Djurhuus et al. 2017). It is therefore difficult to disentangle the bias due to the primers and extraction methods from the effects of biogeography or environmental parameters. However, the use of several primer sets could be also an advantage taking into account that the use of different 
250 primers/markers leads to a better image of the diversity (Shi et al. 2011; Debroas et al. 2017).

251 It's noteworthy that we chose to use the general term fungi even though the phylogeny of some

252 groups cited in this paper is not yet fully elucidated.

\section{Taxonomic resolution}

254 The mean size ( $\sim 400 \mathrm{bp}$ ) of the V4 amplicons gives taxonomy at a relatively broad resolution.

255 For example, more than $90 \%$ of the Chytrids OTUs were identified at the genus level while $99 \%$

256 of the Cryptomycota OTUs are not identified below the phylum level. Altogether, a total of 52

257 genera of fungi were identified within nine phyla (including Incertae sedis). OTUs detected in

258 one ecosystem only, were, for most of them, "unclassified fungi". When considering freshwaters

259 (lakes + rivers), the sequence similarity of Cryptomycota OTUs was generally $<80 \%$ to that of

260 sequences available in the SILVA database whereas for Chytrids OTUs, this sequence similarity

261 was on average 87\%. Except for the Chytrids, fungal sequences found in rivers were

262 characterized by lower similarities than the ones found in lakes suggesting for example that

263 Dikarya are less known in rivers.

\section{Fungal communities in freshwater habitats}

265 When proper analytical treatment is applied, meta-analyses are powerful analytical tools to 266 decipher the structure and ecology of microbial communities (ArchMiller et al., 2015). When 267 analyzing the global microbial eukaryotic diversity in freshwaters, using the same dataset as in 268 our study, Debroas et al. (2017) showed that fungi represented 17\% of this diversity. Freshwater

269 fungi, analyzed in this paper, were affiliated to nine phyla, revealing the great richness that can 270 be captured by the use of different universal $18 \mathrm{~S}$ primers. Considering OTUs, Ascomycota and 271 Basidiomycota (ya) were the most represented phyla in this dataset. The dominance of Dikarya is 272 not usual in freshwater lakes. Indeed, the general assumption is that basal fungi (especially 273 Chytrids) dominate the fungal community composition (Monchy et al. 2011, Panzer et al. 2015; 274 Comeau et al. 2016; Rojas-Jimenez et al. 2017) while Dikarya tend to be dominant in marine 275 ecosystems (Panzer et al. 2015). It's worth mentioning that Dikarya represented 26\% of the 276 fungal reads and present the lowest richness in freshwater. However, the low observed richness 277 could be due to the marker use here which is relatively less resolving for this group than others 278 we've surveyed (Schoch et al. 2012). The great majority of the Ascomycota OTUs fall indeed 
279 within the Pezizomycotina which include 32,000 species (Kirk et al. 2001). Pezizomycotina 280 contains filamentous species that are ecologically diverse and the most represented class is that 281 of Dothideomycetes, which can have terrestrial and aquatic members (Shearer et al. 2009). 282 Terrestrial filamentous fungi (e.g. associated or not with plants) can be introduced into lakes 283 through spores and pieces of mycelia during inflowing stream, rainwater and wind events 284 (Voronin, 2014). Most of the time these fungi fail to establish stable population in aquatic 285 environments (Graupner et al. 2017). Consequently, it is difficult to know if these fungi are truly 286 aquatic (Wurzbacher et al., 2010). However, the rRNA analysis (8 lakes dataset) showed that 287 these fungi were active in freshwater lakes. Filamentous fungi could also be associated with

288

289

290

291

292

293

294

295

296

297

298

299

300

301

302

303

304

305

306

307

308

309 roots of aquatic macrophytes (De Marin et al. 2009; Beck-Nielsen and Madsen, 2001), similarly to fungi associated with roots of terrestrial plants. However, there is little knowledge about fungi in submerged roots. Pleosporales were also well represented. Species in this order inhabit various ecosystems, and are known as saprobes that decay plant material in freshwater (Shearer et al. 2009) and marine habitats (Suetrong et al. 2009). The rest of the Ascomycota OTUs belongs to Ascomycota yeasts. These yeasts live as saprobes, often in association with plants and animals. They are well distributed in deep-sea regions (Bass et al., 2007; Nagahama et al., 2011) and oxygen-depleted ecosystems (Takishita et al., 2007). Moreover, numerous Ascomycota are known to be pathogens of algae in marine systems (Kohlmeyer \& Kohlmeyer 1979; Kubanek et al. 2003).

Interestingly, a great number of Basidiomycota sequences were detected in our dataset. Even though recent molecular data suggest that the Basidiomycota diversity might be high in aquatic ecosystems (Richards et al. 2012; Panzer et al. 2015), less than 100 described species were isolated from aquatic sources (Shearer et al. 2007; Jones et al. 2012). Some OTUs were affiliated to the three major clades of Basidiomycota: Agaricomycotina, which represented more than half of the Basidiomycota OTUs and includes the vast majority of edible mushrooms forming spores and Pucciniomycotina as well as Ustilaginomycotina, which are known as plant parasites and sometimes have been found in association with aquatic invertebrates. For example, several OTUs are affiliated with the basidiomycete yeast Rhodotorula (Pucciniomycotina). It has been found in deep-sea tubeworms and bivalves as well as in different environmental DNA surveys (Nagahama et al. 2003). The rRNA sequencing surprisingly showed that the Agaricomycotina were the most active group within the Basidiomyota while the Ustilaginomycotina did not show any active 
310 OTUs. Even though Dikarya are identified as inhabiting terrestrial environments they were found

311 active in freshwater lakes. They can therefore be directly involved in the trophic food web

312 functioning. There could also be a continuous flow of active terrestrial Dikarya to the aquatic

313 ecosystems through flooding for example (Röhl et al. 2017). Another explanation could be that

314 these organisms were not active despite their high rRNA content. Chytridiomycota and

315 Cryptomycota were also well represented in this freshwater dataset. Together they represent

316 almost a third of the fungal OTUs/reads. These two phyla are included in the so-called DMF

317 (Dark Matter Fungi), which encompass uncultured taxa belonging to early diverging branches of

318 the fungal tree (Grossart et al. 2015). Chytridiomycota are well documented in freshwater lakes

319 where they play various roles as saprobes and parasites (mainly of phytoplankton) (Panzer et al.

320 2015). Chytridiomycota zoospores are also a food resource for zooplankton (mycoloop) (Gleason

321 et al. 2008). Chytridiomycota seemed to be relatively less active than Cryptomycota and

322 Dikarya, only $8.4 \%$ of their OTUs were found active. Because of their undersampling, little is

323 known about Chytridiomycota in rivers. Nevertheless, a recent study showed high abundances of

324 Chytridiomycota zoospores in the Colombia river (Maier and Peterson, 2016).

325 In contrast to Chytridiomycota, Cryptomycota were discovered more recently in aquatic 326 environments (Jones et al. 2011). Cryptomycota have been reported to account for only 0.02$3274.5 \%$ of the total $18 \mathrm{~S}$ rDNA sequences found in aquatic ecosystems (Livermore and Mattes, 328 2013). This group is highly-diverse (15 clades have been identified (Lazarus and James, 2015), 329 but it almost exclusively known through environmental sequences. These fungi are found in a 330 large range of ecosystems (Jones et al. (2011); Livermore et al. (2013); Lazarus and James 331 (2015)) without any specific clades to freshwater, soil, or marine systems (Livermore and 332 Mattes, 2013). In freshwater a few investigations showed that they could act as parasites of 333 phytoplankton (Jones et al. 2011, Ishida et al. 2015). Using fluorescent in situ hybridization, our 334 investigations showed, indeed, several associations between diatoms (Asterionella) and 335 Cryptomycota (Figure 5) in a freshwater lake. All estimators suggest that Cryptomycota is the 336 richest group in both lakes and rivers. In term of rDNA OTUs abundance, Cryptomycota 337 dominate over Chytridiomycota in rivers. Moreover, Cryptomycota OTUs were usually less than $33880 \%$ similar to the sequences deposited in databases in both lake and rivers and can't be 339 identified at a high taxonomic resolution. Moreover, 17\% of the Cryptomycota OTUs were 340 active in Freshwater lakes and represented a large proportion of the total rRNA reads. This 
341 shows the need to enhance reference databases by increasing the sampling effort in freshwater

342 ecosystems, especially streams.

343 Fungal distribution across ecosystems

344 The low number of shared fungal OTUs among the diverse studies considered here suggests a

345 high diversity and a low proportion of generalist fungi. Only a few fungal lineages were assigned

346 at the species or genus level suggesting that even the more common lineages are poorly known

347 or are missing from databases. $61 \%$ of the OTUs were found in one lake only. Interestingly, most

348 of these OTUs have very weak supported affiliation (i.e. environmental samples). We cannot

349 exclude the possibility that increasing further the sampling depth may lead to identify a higher

350 number of OTUs characterized by a broader distribution. Simon et al. (2015) highlighted the

351 importance of temporal surveys in the study of the microbial diversity. Such approach helps at

352 detecting taxa that can occur at low frequency.

353 Our analysis showed that a very small number of fungal OTUs $(5.5 \%)$ is shared between marine 354 and freshwater ecosystems while up to $23 \%$ of the OTUs were shared between lakes and rivers.

355 This confirms the data of Panzer et al. (2015) showing that freshwater fungal community 356 structure differed significantly from all other habitats and of Logares et al. (2009) showing that

357 fungi usually group into distinct marine and freshwater phylogenetic clusters. Molecular results 358 from SSU rRNA and ITS1 region analyses also support the idea of a transition in fungal 359 community structure along a salinity gradient (Burgaud et al. 2013). Until recently, marine fungi

360 showed low diversity and abundance especially in the photic zone. However HTS has suggested 361 that marine ecosystems contain more fungal diversity than previously thought (Richards et al. 362 2015). For example, Livermore et al. (2013) found evidence of considerable Cryptomycota 363 diversity at the marine surface and Richards et al. (2015) showed that marine fungi include a 364 large number of chytrid that had not been described before.

\section{Conclusion}

366 This study represents the first in-depth inventory of published 18S rRNA gene sequence data on

367 freshwater fungi and also adds some new data regarding potential activity of fungi in freshwater 368 lakes. However, our knowledge on this phylogenetic group remains very limited. This is partly 
369 due to methodological limitations such as inaccurate methods for fungal morphological

370 identification, non-specific molecular markers and to the lack of well-represented reference

371 databases. We are indeed currently limited by the low representation of functional genes in the

372 databases as well as the lack of sequenced fungal genomes, which prevent the exploration of the

373 metabolic capacities of aquatic fungi through metagenomic and metatranscriptomic studies for

374 instance, even though ongoing projects will likely reverse this bias such as the 1000 Fungal

375 Genomes Project (Grigoriev et al. 2014). Our study highlights the need to increase the sampling

376 effort at a global scale by conducting surveys in the most diverse set of aquatic ecosystems as

377 possible, by exploring the diverse putative habitats (e.g. immerged plants, aquatic vertebrates,

378 littoral, sediments, pelagic) as well as increasing the resolution of the fungal diversity by

379 realizing temporal surveys at the scale of single ecosystems. For example, Wurzbacher et al.

380 (2016) discovered a high biodiversity of fungi and a large number of ecological niches in a single

381 lake. They also showed that the sediment and biofilms are hotspots of aquatic fungal diversity.

382 Moreover, a large part of this fungal diversity seems to be active in lacustrine ecosystems

383 (Debroas et al. 2015; Lepere et al. 2016). Furthermore, considering that only 1112 species of

384 marine fungi have been described while $71 \%$ of the planet is covered by marine water (Jones et

385 al. 2015), it is very likely that the global fungal diversity is greatly underestimated in aquatic 386 systems.

387

388

389

390

391 392

393

394

395

396

397

398

\section{Tables and figures}

Table 1 : High throughput sequencing (HTS) data used in this analysis

Table 2: Richness of main taxonomic groups of fungi in freshwater ecosystems

Figure 1: Rarefaction curves for lakes, rivers and freshwater ecosystems (rivers + lakes) computed from fungal OTUs

Figure 2: Taxonomic identities of fungal OTUs (a) and reads (b) in freshwaters

Figure 3: Abundance (Number of reads) of top 32 fungal OTUs. The identity number of the respective OTU is shown below the bars. Colours represent the fungal phyla and the numbers at the top of the bars represent the numbers of lakes where the OTU can be found. 
399 Figure 4: \% of active fungal OTUs (i.e. DNA OTUs found in the RNA dataset)(a), \% of active

400

401

402

403

404

405

406

407

408

409

410

411

412

413

414

415

416

417

418

419

420

421

422

423

424

425

426

427

428

429

430

431

432

433

434

435

436

437

438

Basidiomycota (grey) and Ascomycota (black) OTUs (b).

Figure 5: Micrographs showing Cryptomycota cells (targeted with the LKM11-01 probe, Mangot et al. 2009) attached to the diatom Asterionella (21/05/2015 Aydat lake, France).

\section{Supplementary materials}

Sup Figure 1: Taxonomic identities of Ascomycota (a) and Basidiomycota (b) OTUs in freshwater

Sup Figure 2: Venn diagram of the number of OTUs shared between lakes, rivers and marine environments

Sup Figure 3: OTUs repartition within the major taxonomic groups in lakes and rivers

Sup Table 1: Numbers of clean reads affiliated to eukaryotes for each study

Sup Table 2: Sources of the data used in this analysis

\section{References}

ArchMiller AA, Bauer EF, Koch RE, Wijayawardena BK, Anil A, Kottwitz JJ, Munsterman AS, Wilson AE. 2015. Formalizing the definition of meta-analysis in Molecular Ecology. Molecular Ecology 24:4042-4051

Arfi Y, Buee M, Marchand C, Levasseur A, Record E. 2012. Multiple markers pyrosequencing reveals highly diverse and host-specific fungal communities on the mangrove trees Avicennia marina and Rhizophora stylosa. FEMS Microbiol. Ecol 79: 433444

Artigas J, Pascault N, Bouchez A, Chastain J, Debroas D, Humbert JF, Leloup J, Tadonleke RD, Ter Halle A. 2014. Pes Comparative sensitivity to the fungicide tebuconazole of biofilm and plankton microbial communities in freshwater ecosystems. Sci. Total. Environ 15:468469

Bass D, Howe A, Brown N, Barton H, Demidova M, Michelle H, Li L, Sanders H, Watkinson SC, Willcock S, Richards TA. 2007. Yeast forms dominate fungal diversityin the deep oceans. Proc. Biol. Sci 274:3069-77

Bass D, Richards TA. 2011. Three reasons to re-evaluate fungal diversity 'on Earth and in the ocean'. Fungal biology reviews $25: 159 \mathrm{e} 164$

Beck-Nielsen D, Madsen TV. 2001. Occurrence of vesicular-arbuscular mycorrhiza in aquatic macrophytes from lakes and streams. Aquat. Bot 71: 141-148.

Blackwell M. 2011. The fungi: 1, 2, 3 ... 5.1 million species? Am. J. Bot. 98:426-38. doi: 10.3732/ajb.1000298.

Bricheux G, Morin L, Le Moal G, Coffe G, Balestrino D, Charbonnel N, Bohatier J, Forestier C. 2013. Pyrosequencing assessment of prokaryotic and eukaryotic diversity in biofilm 
communities from a French river. Microbiology Open 2:402-14. of Asterionella formosa Hass. in relation to fungal epidemics. New. Phytol 47:238-261 Caporaso JG, Lauber CL, Walters WA, Berg-Lyons D, Lozupone CA, Turnbaugh PJ, Fierer N, Knight R. 2010. Global patterns of $16 \mathrm{~S}$ rRNA diversity at a depth of millions of sequences per sample. PNAS 108: 4516-4522 Charvet S, Vincent WF, Comeau A, Lovejoy C. 2012. Pyrosequencing analysis of the protist communities in a High Arctic meromictic lake: DNA preservation and change. Front Extreme Microbiol 3:422. 735

449 Charvet S, Vincent WF, Lovejoy C. 2014. Effects of light and prey availability on Arctic freshwater protist communities examined by high-throughput DNA and RNA sequencing. FEMS Microbiol. Ecol 88:550-64. fungal sequences in diverse marine and freshwater habitats. Sci Rep. 2:30120

459 Dawson SC, Pace NR. 2002. Novel kingdom-level eukaryotic diversity in anoxic environments. Proc. Natl. Acad. Sci. USA 99:8324-29

Debroas D, Hugoni M, Domaizon I. 2015. Evidence for an active rare biosphere within freshwater protists community. Mol. Ecol. 24:1236-1247.

Debroas D, Domaizon I, Humbert JF, Jardillier L, Lepère C, Oudart A, Taib N. 2017. Overview of freshwater microbial eukaryotes diversity: a first analysis of publicly available metabarcoding data. FEMS Microbiol. Ecol. 1:93(4) doi: 10.1093/femsec/fix023. arbuscularmycorrhizal fungi and dark septate fungi in aquatic macrophytes in a tropical riverflood plain system. Aquat. Bot.91: 13-19.

464 Dixon P. 2003. VEGAN, a package of R functions for community ecology. J.Veg. Sci. 14:927-930. DB, Michisaki R, Breitbart M, Boehm AB, Chavez FP. 2017. Evaluation of Filtration and DNA Extraction Methods for Environmental DNA Biodiversity Assessments across Multiple Trophic Levels. Frontiers in Marine Science. doi.org/10.3389/fmars.2017.00314

Duarte S, Barlocher F, Trabulo J, Cassio F, Pascoal C. 2015. Stream-dwelling fungal decomposer communities along a gradient of eutrophication unraveled by 454 pyrosequencing. Fungal Diversity 70: 127-148.

Dunthorn M, Klier J, Bunge J, Stoeck T. 2012. Comparing the Hyper16Variable V4 and V9 Regions of the Small Subunit rDNA for Assessment of Ciliate Environmental Diversity. $J$. Eukaryot. Microbiol. 59:185-187

Edgar RC. 2013. UPARSE: highly accurate OTU sequences from microbial amplicon reads. Nat. Methods. 10:996-8.

Edgar RC, Haas BJ, Clemente JC, Quince C, Knight R. 2011. UCHIME improves sensitivity and speed of chimera detection. Bioinformatics 27:2194-200. doi: 10.1093/bioinformatics/btr381.

Gao Z, Johnson ZI, Wang GY. 2010. Molecular characterization of the spatial diversity and novel line- ages of mycoplankton in Hawaiian coastal waters. ISME J. 4: 111-120. doi: 10.1038/ismej.2009.

Giongo A, Crabb DB, Davis-Richardson AG, Chauliac D, Mobberley JM, Gano KA, Mukherjee N, Casella G, Roesch LF, Walts B, Riva A, King G, Triplett EW. 2010. 
485

486

487

488

489

490

491

492

493

494

495

496

497

498

499

500

501

502

503

504

505

506

507

508

509

510

511

512

513

514

515

516

517

518

519

520

521

522

523

524

525

526

527

528

529

530

PANGEA: pipeline for analysis of next generation amplicons. ISME J. 4:852-861.

Gleason FH, Kagami M, Lefèvre E, Sime-Ngando T. 2008. The ecology of chytrids in aquatic ecosystems: roles in food web dynamics. Fungal Biol. Rev. 2:17-25

Graupner N, Röhl O, Jensen M., Beisser D., Begerow D, Boenigk J. 2017. Effects of shortterm flooding on aquatic and terrestrial protist communities - a mesocosm approach. Aquatic Microbial Ecology 80 :257-272

Grigoriev IV, Nikitin R, Haridas S, Kuo A, Ohm R, Otillar R, Riley R, Salamov A, Zhao X, Korzeniewski F, Smirnova T, Nordberg H, Dubchak I, Shabalov I. 2014. MycoCosm portal: gearing up for 1000 fungal genomes. Nucleic Acids Res. doi: 10.1093/nar/gkt1183

Grossart HP, Wurzbacher C, James TY, Kagami M. 2015. Discovery of dark matter fungi in aquatic ecosystems demands a reappraisal of the phylogeny and ecology of zoosporic fungi. Fungal Ecology 19:28-38.

Grossart HP, Rojas-Jimenez K. 2016. Aquatic fungi: targeting the forgotten in microbial ecology. Current Opinion in Microbiology 31:140-145

Gulis V, Kuehn KA, Suberkropp K. 2009. Fungi. In: Likens EG (ed) Encyclopedia of inland waters. Academic Press, Oxford, p 233-243

Hassett BT, Gradinger R. 2016. Chytrids dominate arctic marine fungal communities. Environ Microbiol 18:2001-9.

Hawksworth DL. 2001. The magnitude of fungal diversity: the 1.5 million species estimate revisited. Mycol. Res. 105:1422-32.

Hugoni M, Taib N, Debroas D, Domaizon I, Jouan Dufournel I, Bronner G, Salter I, Agogué H, Mary I and Galand PE. 2013. Structure of the rare archaeal biosphere and seasonal dynamics of active ecotypes in surface coastal waters. PNAS 110 :6004-6009.

Hugoni M, Domaizon I, Taib N, Biderre-petit C, Agogué H, Galand PE, Debroas D, Mary I. 2015. Temporal dynamics of active Archaea in oxygen-depleted zones of two deep lakes. Environ Microbiol Rep 7:321-9.

Ishii N, Ishida S, Kagami M. 2015. PCR primers for assessing community structure of aquatic fungi including Chytridiomycota and Cryptomycota. Fungal Ecology 13:33-43

Ishida S, Nozaki D, Grossart HP, Kagami M. 2015. Novel basal, fungal lineages from freshwater phytoplankton and lake samples. Environ. Microbiol. Rep. 7:435-41.

James TY, Kauff F, Schoch CL, Matheny PB, Hofstetter V, Cox CJ, Celio G, Gueidan C, Fraker E, Miadlikowska J, Lumbsch HT, Rauhut A, Reeb V, Arnold AE, Amtoft A, Stajich JE, Hosaka K, Sung GH, Johnson D, O'Rourke B, Crockett M, Binder M, Curtis JM, Slot JC, Wang Z, Wilson AW, Schüssler A, Longcore JE, O'Donnell K, Mozley-Standridge S, Porter D, Letcher PM, Powell MJ, Taylor JW, White MM, Griffith GW, Davies DR, Humber RA, Morton JB, Sugiyama J, Rossman AY, Rogers JD, Pfister DH, Hewitt D, Hansen K, Hambleton S, Shoemaker RA, Kohlmeyer J, Volkmann-Kohlmeyer B, Spotts RA, Serdani M, Crous PW, Hughes KW, Matsuura K, Langer E, Langer G, Untereiner WA, Lücking R, Büdel B, Geiser DM, Aptroot A, Diederich P, Schmitt I, Schultz M, Yahr R, Hibbett DS, Lutzoni F, McLaughlin DJ, Spatafora JW, Vilgalys R. 2006. Reconstructing the early evolution of Fungi using a six-gene phylogeny. Nature 443: 818-822.

Jebaraj CS, Raghukumar C, Behnke A, Stoeck T. 2010. Fungal diversity in oxygen-depleted regions of the Arabian Sea revealed by targeted environmental sequencing combined with cultivation. FEMS Microbiol. Ecol. 71:399-412

Jobard M, Rasconi S, Sime-Ngando T. 2010. Diversity and functions of microscopic fungi: a missing component in pelagic food webs. Aquat. Sci. 72: 255-268. 
531

532

533

534

535

536

537

538

539

540

541

542

543

544

545

546

547

548

549

550

551

552

553

554

555

556

557

558

559

560

561

562

563

564

565

566

567

568

569

570

571

572

573

574

575

576

Jones MDM, Forn I, Gadelha C, Egan MJ, Bass D, Massana R, Richards TA. 2011. Discovery of novel intermediate forms redefines the fungal tree of life. Nature 474: 200-203. Jones EBG, Suetrong S, Sakayaroj J, Bahkali A, Abdel-Wahab M, Boekhout T, Pang K-L. 2015. Classification of marine Ascomycota, Basidiomycota, Blastocladiomycota and Chytridiomycota. Fungal Divers. 73: 1-72.

Jones EBG, Fell JW. Basidiomycota. 2012. In: Jones EBG, Pang KL, editors. Marine Fungiand fungal-like organisms. Berlin Boston: Walter de Gruyter. pp. 49-64

Kammerlander B, Breiner H-W, Filker S, Sommaruga R, Sonntag B, Stoeck T, .2015. High diversity ofprotistan plankton communities in remote high mountain lakes in the European Alps and the Himalayan mountains. FEMS Microbiol. Ecol. 91:fiv010.

Karpov SA, Mamkaeva MA, Aleoshin VV, Nassonova E, Lilje O, Gleason FH. 2014. Morphology, phylogeny, and ecology of the aphelids (Aphelidea, Opisthokonta) and proposal for the new superphylum Opisthosporidia. Front. in Microbiol. 28:112

Kembel SW, Cowan PD, Helmus MR, Cornwell WK, Morlon H, Ackerly DD, Blomberg SP, Webb CO. 2010. Picante: R tools for integrating phylogenies and ecology. Bioinformatics 26:1463-1464.

Kirk, PM, Cannon, PF, David, JC, Stalpers, JA. 2001. Ainsworth and Bisby's Dictionary of the Fungi, 9th ed. CAB International, Wallingford, UK.

Korajkic A, Parfrey LW, McMinn BR, Baeza YV, VanTeuren W, Knight R, Shanks OC. 2015. Changes in bacterial and eukaryotic communities during sewage decomposition in Mississippi river water. Water Res. 69:30-39.

Kohlmeyer J, Kohlmeyer E. Marine Mycology: The Higher Fungi. New York: Academic 1979.

Kubanek J, Jensen PR, Keifer PA, Sullards MC, Collins DO, Fenical W. 2003. Seaweed resistance to microbial attack: a targeted chemical defence against marine fungi. Proc. Natl. Acad. Sci. USA 100:6916-21

Lai XT, Cao LX, Tan HM, Fang S, Huang YL, Zhou S. 2007. Fungal communities from methane hydrate- bearing deep-sea marine sediments in South China Sea. ISME J. 1: 756762. PMID: 18059498

Lazarus KL, James TY. 2015. Surveying the biodiversity of the Cryptomycota using a targeted PCR approach. Fungal Ecology 14:62-70.

Le Calvez T, Burgaud G, Mahe S, Barbier G, Vandenkoornhuyse P. 2009. Fungal diversity in deep-sea hydrothermal ecosystems. Appl Environ Microbiol 75:6415-21

LefèvreE, Roussel B, Amblard C, Sime-Ngando T. 2008. The molecular diversity of freshwater picoeukaryotes reveals high occurrence of putative parasitoids in the plankton. PLoS ONE 3, e2324. (doi:10.1371/journal.pone.0002324)

Lepère $\quad$ C, Domaizon I, Debroas $\quad$ D. 2008 . Unexpected importance of potential parasites in the composition of freshwater smalleukaryote community. Appl. Environ. Microbiol. 74: 2940-2949.

Lepère C, Domaizon I, Hugoni M, Vellet A, Debroas D. 2016. Diversity and dynamics of active microbial eukaryotes in the anoxic zone of a freshwater meromictic lake (Pavin, France). Front. in Microbiol. doi: 10.3389/fmicb.2016.00130.

Lepère $\mathrm{C}$, Ostrowski M, Hartmann M, Zubkov MV, Scanlan DJ. 2015. In situ associations between marine photosynthetic picoeukaryotes and potential parasites - a role for fungi? Environmental Microbiology Reports 8:445-51 
577

578

579

580

581

582

583

584

585

586

587

588

589

590

591

592

593

594

595

596

597

598

599

600

601

602

603

604

605

606

607

608

609

610

611

612

613

614

615

616

617

618

619

620

621

622

Liu Z, DeSantis TZ, Andersen GL, Knight R. 2008. Accurate taxonomy assignments from 16S rRNA sequences produced by highly parallel pyrosequencers. Nucleic Acids Research. 36(18):e120. doi: 10.1093/nar/gkn491

Livermore JA, Mattes TE. 2013. Phylogenetic detection of novel Cryptomycota in an Iowa (United States) aquifer and from previously collected marine and freshwater targeted highthroughput sequencing sets. Environmental Microbiology 15: 2333-2341. doi: 10.1111/1462-2920.

Logares R, Bråte J, Bertilsson S, Clasen JL, Shalchian-Tabrizi K, Rengefors K. 2009. Infrequent marine-freshwater transitions in the microbial world. Trends Microbiol 17:414-22. doi: 10.1016/j.tim.2009.05.010.

Lücking R, Huhndorf S, Pfister DH, Plata ER, Lumbsch HT. 2009. Fungi evolved right on track. Mycologia 101: 810-22.

Maier MA, Peterson TD. 2016. Enumeration of parasitic chytrid zoospores in the Columbia River via quantitative PCR. Appl. Environ. Microbiol. 82:3857-3867.

Mangot J-F, Domaizon I, Taib N, Marouni N, Duffaud E, Bronner G, Debroas D. 2013. Short-term dynamics of diversity patterns: evidence of continual reassembly within lacustrine small eukaryotes. Environ. Microbiol. 15:1745-58.

Monchy S, Sanciu G, Jobard M, Rasconi S, Gerphagnon M, Chabé M, Cian A, Meloni D, Niquil N, Christaki U, Viscogliosi E, Sime-Ngando T. 2011. Exploring and quantifying fungal diversity in freshwater lake ecosystems using rDNA cloning/sequencing and SSU tag pyrosequencing. Environ Microbiol. 13:1433-53.

Mora C, Tittensor DP, Adl S, Simpson AG, Worm B. 2011. How many species are there on Earth and in the ocean? PLoS Biol 9, e1001127.

Massana R, Pedro's-Alio C. 2008. Unveiling new microbial eukaryotes in the surface ocean. Curr. Opin. Microbiol. 11:213-18

Nagahama T, Takahashi E, Nagano Y, Abdel-Wahab MA, Miyazaki M. 2011. Molecular evidence that deep-branching fungi are major fungal components in deep-sea methane coldseep sediments. Environ. Microbiol. 13:2359-70. doi: 10.1111/j.1462-2920.2011.02507.x.

Nagahama T, Hamamoto M, Nakase T, Horikoshi K. 2003. Rhodotorula benthica sp. nov. and Rhodotorula calyptogenae sp. nov., novel yeast species from animals collected from the deep- sea floor, and Rhodotorula lysiniphila sp. nov., which is related phylogenetically. Int J Syst Evol Microbiol 53:897-903

Nikolcheva LG, Cockshutt AM, Barlocher F. 2003. Determining diversity of freshwater fungi on decaying leaves: Comparison of traditional and molecular approaches. Applied and Environmental Microbiology 69: 2548-2554.

Nolte V, Pandey RV, Jost S, Medinger R, Ottenwälder B, Boenigk J, Schlötterer C. 2010. Contrasting seasonal niche separation between rare and abundant taxa conceals the extent of protist diversity. Mol. Ecol. 19:2908-2915.

O’Brien HE, Parrent JL, Jackson JA, Moncalvo J-M, Vilgalys R. 2005. Fungal community analysis bylarge-scale sequencing of environmental samples. Appl Environ Microbiol 71:5544-50

Orsi W, Biddle JF, Edgcomb V. 2013. Deep sequencing of subseafloor eukaryotic rRNA reveals active fungi across marine subsurface provinces. PLoS ONE 8, e56335. doi:10.1371/journal

Panzer K, Yilmaz P, Weiß M, Reich L, Richter M, Wiese J, Schmaljohann R, Labes A, Imhoff JF, Glockner FO. 2015. Identification of habitat-specific biomes of aquatic fungal 
623

624

625

626

627

628

629

630

631

632

633

634

635

636

637

638

639

640

641

642

643

644

645

646

647

648

649

650

651

652

653

654

655

656

657

658

659

660

661

662

663

664

665

666

667

communities using a comprehensive nearly full-length 18S rRNA dataset enriched with contextual data. PLOS ONE 10:e0134377.

Panno L, Bruno M, Voyron S, Anastasi A, Gnavi G, Miserere L, Varese GC. 2013. Diversity, ecological role and potential biotechnological applications of marine fungi associated to the seagrass Posidonia oceanica. New Biotechnology 30: 685-694.

Paradis E, Claude J, Strimmer K. 2004. APE: Analyses of Phylogenetics and Evolution in R language. Bioinformatics 20:289-290.

Pautasso M. 2013. Fungal under-representation is (slowly) diminishing in the life sciences. Fungal Ecology 6: 129-135

Pommier T, Canbäck B, Lundberg P, Hagström A, Tunlid A. 2009. RAMI: a tool for identification and characterization of phylogenetic clusters in microbial communities. Bioinformatics 25:736-742.

Price MN, Dehal PS, Arkin AP. 2010. FastTree 2 - Approximately Maximum-Likelihood Trees for Large Alignments. PLoS ONE 5:e9490.

Pruesse E, Quast C, Knittel K, Fuchs BM, Ludwig W, Peplies J, Glöckner FO. 2007. SILVA: a comprehensive online resource for quality checked and aligned ribosomal RNA sequence data compatible with ARB. Nucleic Acids Res. 35:7188-7196.

Rambold G, Stadler M, Begerow D. 2013. Mycology should be recognized as a field in biology at eye level with other major disciplines - a memorandum. Mycological Progress 12: 455-463.

Richards TA, Jones MDM, Leonard G, Bass D. 2012. Marine fungi: their ecology and molecular diversity. Ann Rev Mar Sci 4: 495-522

Richards TA, Leonard G, Mahé F, Del Campo J, Romac S, Jones MD, Maguire F, Dunthorn M, De Vargas C, Massana R, Chambouvet A. 2015. Molecular diversity and distribution of marine fungi across 130 European environmental samples. Proc. Biol. Sci. 22;282(1819).

Rojas-Jimenez K, Wurzbacher C, Bourne EC, Chiuchiolo A, Priscu JC, Grossart HP. 2017. Early diverging lineages within Cryptomycota and Chytridiomycota dominate the fungal communities in ice-covered lakes of the McMurdo Dry Valleys, Antarctica. Sci. Rep. $7: 15348$.

Schloss PD. 2010. The Effects of Alignment Quality, Distance Calculation Method, Sequence Filtering, and Region on the Analysis of 16S rRNA Gene-Based Studies. PLoS Comput. Biol. 6:e1000844

Schloss PD, Girard R, Martin T, Edwards J, Thrash JC. 2016. The status of the microbial census: an update. bioRxiv 38646.

Schoch CL, Seifert KA, Huhndorf S, Robert V, Spouge JL, Levesque CA, Wen Chen, and Fungal Barcoding Consortium. 2012. Nuclear ribosomal internal transcribed spacer (ITS) region as a universal DNA barcode marker for Fungi. PNAS April 109 : 6241-6246

Seena S, Wynberg N, Bärlocher F. 2008. Fungal diversity during leaf decomposition in a stream assessed through Agaricomycota clone libraries. Fungal Divers. 30:1-14

Shearer CA, Raja HA, Miller AN, Nelson P, Tanaka K, Hirayama K, Marvanová L, Hyde KD, Zhang Y. 2009. The molecular phylogeny of freshwater Dothideomycetes. Stud. Mycol. 64:145-153

Shearer CA, Descals E, Kohlmeyer B, Kohlmeyer J, Marvanova L, Padgett D, Porter D, Raja HA, Schmit JP, Thorton HA, Voglymayr H . 2007. Fungal biodiversity in aquatic habitats. Biodiversity and Conservation 16: 49-67 
Scheffers BR, Joppa LN, Pimm SL, Laurance WF. 2012. What we know and don't know about Earth's missing biodiversity. Trends Ecol. Evol. 27:501-10. doi: 10.1016/j.tree.2012.05.008. Review. Erratum in: Trends Ecol. Evol. 27:712-3. 
714

715

716

717

718

719

720

721

722

723

724 
Figure 1

Rarefaction curves for lakes, rivers and freshwater ecosystems (rivers + lakes) computed from fungal OTUs

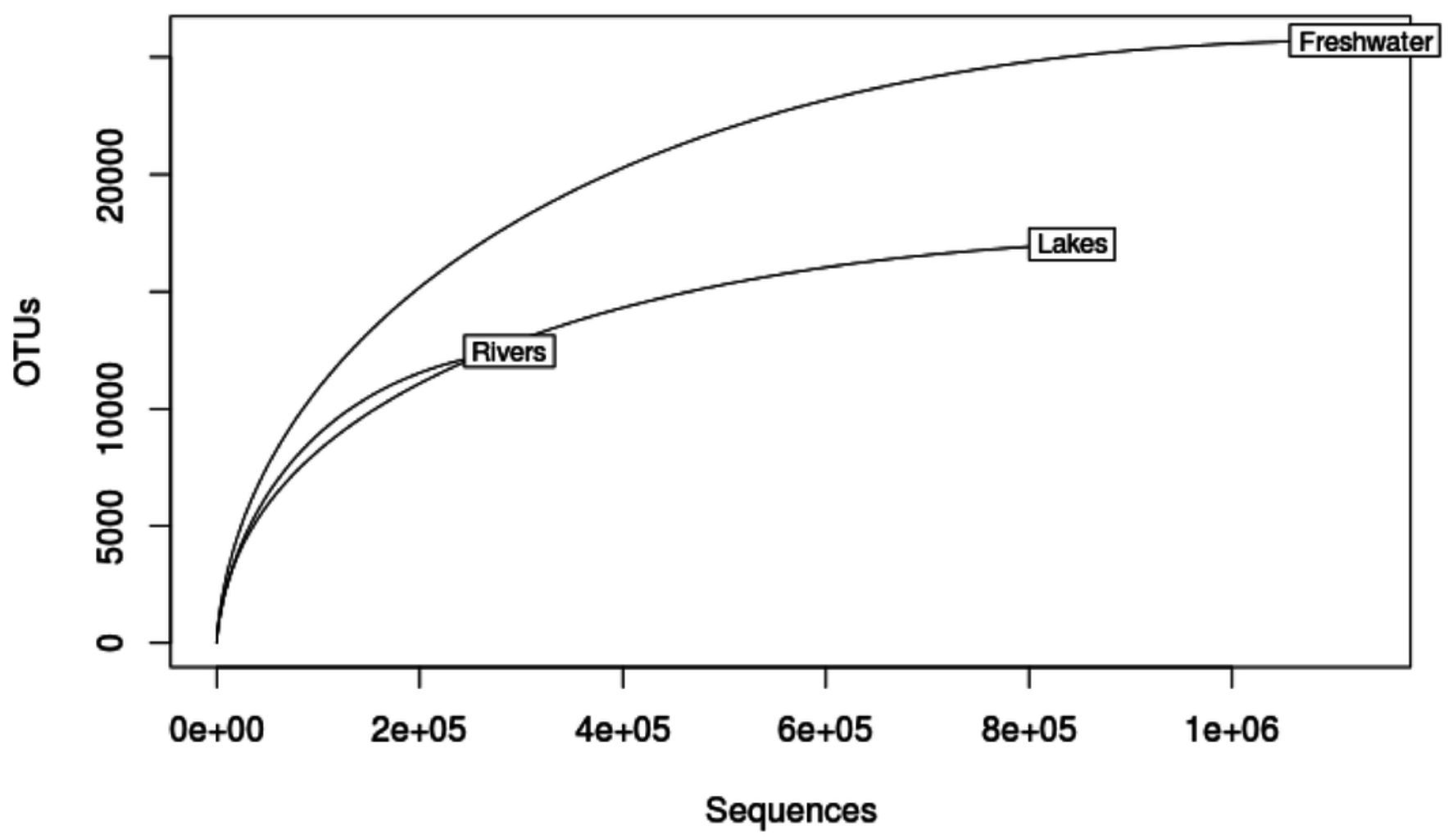




\section{Table 1 (on next page)}

Taxonomic identities of fungal OTUs (a) and reads (b) in freshwaters 


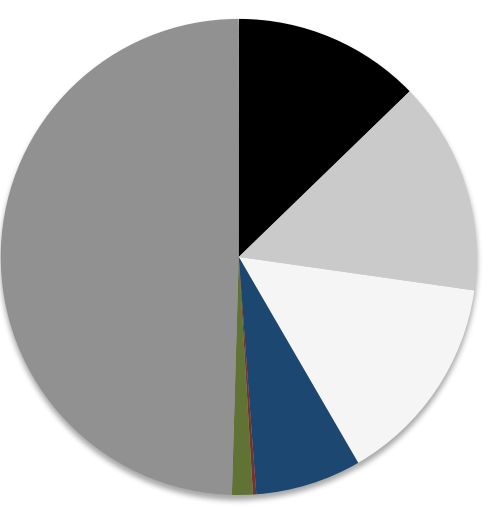

a
Mlastocladiomycota

- Chytridiomycota

Cryptomycota

Ascomycota

- Basidiomycota

- Glomeromycota

- Neocallimastigomycota

unclassified

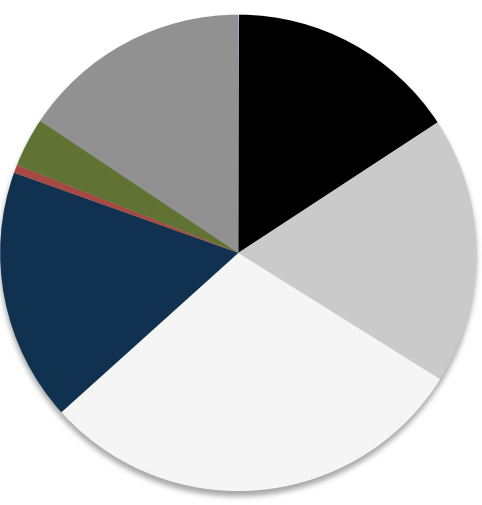

b 


\section{Table 2 (on next page)}

Abundance (Number of reads) of top 32 fungal OTUs. The identity number of the respective OTU is shown below the bars. Colours represent the fungal phyla and the numbers at the top of the bars represent the numbers of lakes where the OTU can be found. 


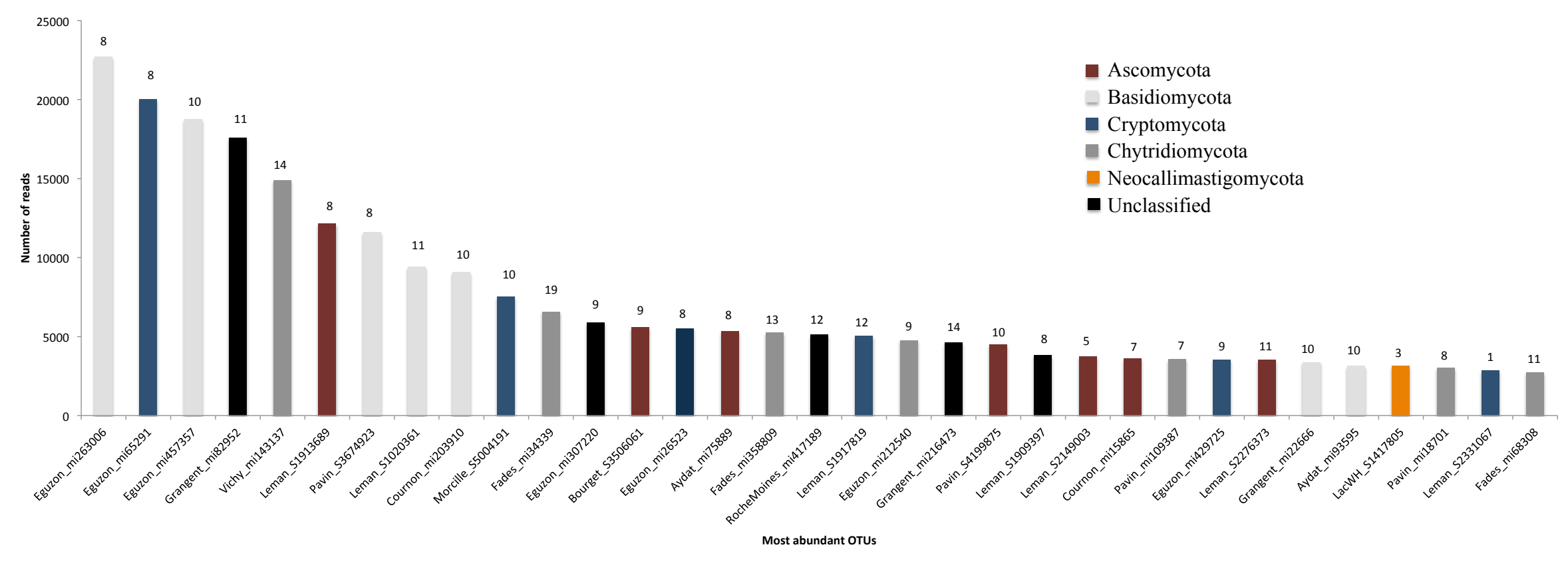




\section{Table 3(on next page)}

$\%$ of active fungal OTUs (i.e. DNA OTUs found in the RNA dataset)(a), \% of active Basidiomycota (grey) and Ascomycota (black) OTUs (b). 

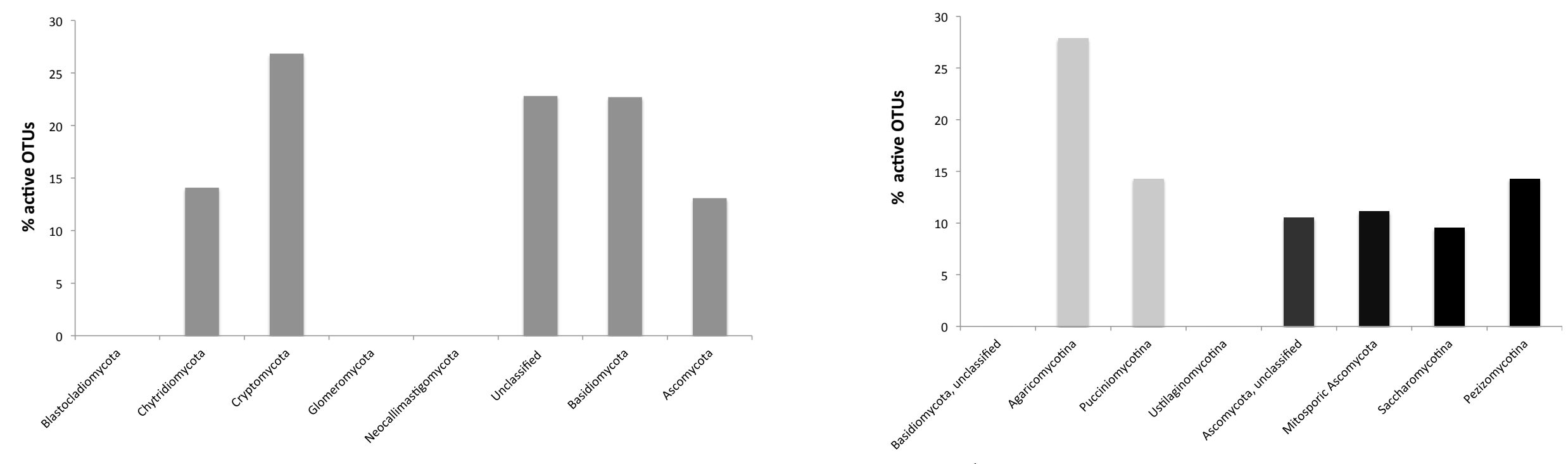


\section{Figure 2}

Micrographs showing Cryptomycota cells (targeted with the LKM11-01 probe, Mangot et al. 2009) attached to the diatom Asterionella (21/05/2015 Aydat lake, France).

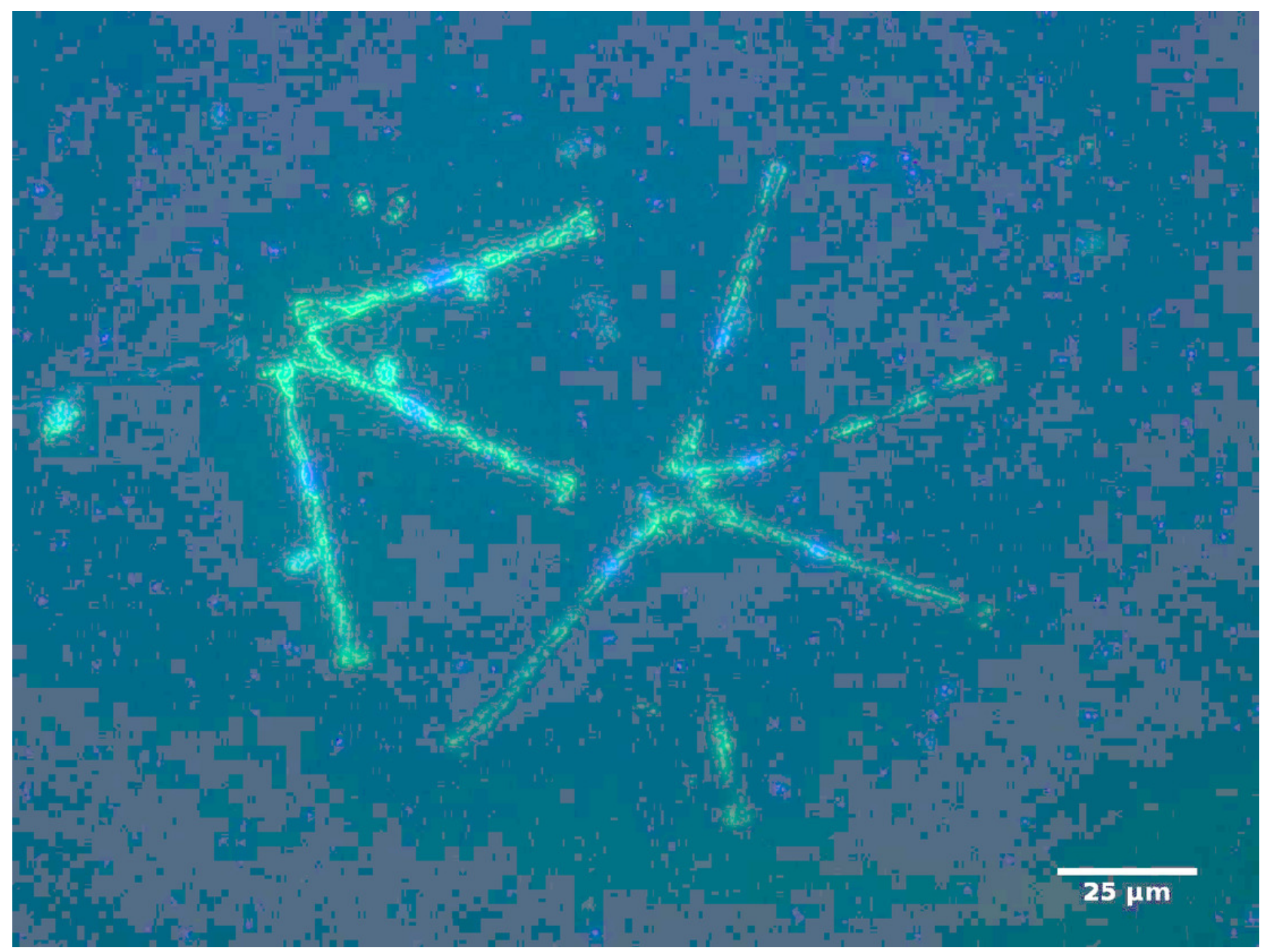




\section{Table 4(on next page)}

High throughput sequencing (HTS) data used in this analysis 


\begin{tabular}{|c|c|c|c|c|c|}
\hline Pefif & References & $\begin{array}{l}\text { Geographic } \\
\text { area } M-2-\end{array}$ & $\begin{array}{c}\text { Size } \\
\text { fraction }\end{array}$ & $\begin{array}{l}\text { Primers } \\
\text { t to be }\end{array}$ & $\begin{array}{c}\text { HTS } \\
\text { reviewte }\end{array}$ \\
\hline & $\begin{array}{l}\text { Freshwater environments used } \\
\text { for taxonomic affiliation }\end{array}$ & & & & \\
\hline \multicolumn{6}{|l|}{ Lakes } \\
\hline Pavin & Debroas et al. (2015) & $\begin{array}{l}\text { Massif } \\
\text { central } \\
\text { (France) }\end{array}$ & $\begin{array}{l}0.2-5 \\
\mu \mathrm{m}\end{array}$ & $\begin{array}{l}\text { NSF573- } \\
\text { NSR951 }\end{array}$ & 454 \\
\hline Bourget & Debroas et al. (2015) & Alps (France) & $\begin{array}{l}0.2-5 \\
\mu \mathrm{m}\end{array}$ & $\begin{array}{l}\text { NSF573- } \\
\text { NSR951 }\end{array}$ & 454 \\
\hline Leman & Mangot et al (2013) & Alps (France) & $\begin{array}{l}0.2-5 \\
\mu \mathrm{m}\end{array}$ & $\begin{array}{l}\text { NSF573- } \\
\text { NSR951 }\end{array}$ & 454 \\
\hline LakeA & Charvet et al. (2012) & Arctic & $0.2-3 \mu \mathrm{m}$ & $\begin{array}{l}\text { E572F- } \\
\text { E1009R }\end{array}$ & 454 \\
\hline LakeWH & Charvet et al. (2014) & Arctic & & $\begin{array}{l}\text { E572F- } \\
\text { E1009R }\end{array}$ & 454 \\
\hline $\begin{array}{l}\text { Aydat, Anterne, } \\
\text { Godivelle, Pavin, } \\
\text { Bourget, Sep, Villerest }\end{array}$ & $\begin{array}{l}\text { Lepere et al (2013) and Taib et } \\
\text { al. (2013) }\end{array}$ & $\begin{array}{l}\text { Massif } \\
\text { central } \\
\text { (France) and } \\
\text { Alps }\end{array}$ & $\begin{array}{l}0.2-5 \\
\mu \mathrm{m}\end{array}$ & $\begin{array}{l}\text { NSF573- } \\
\text { NSR951 }\end{array}$ & 454 \\
\hline LaClaye & \multirow{3}{*}{$\begin{array}{l}\text { Simon et al. (2014) and Simon } \\
\text { et al (2015) }\end{array}$} & \multirow{3}{*}{$\begin{array}{l}\text { Chevreuse } \\
\text { Valley } \\
\text { (France) }\end{array}$} & \multirow{3}{*}{$\begin{array}{l}0.2-5 \\
\mu \mathrm{m}\end{array}$} & \multirow{3}{*}{$\begin{array}{l}\text { EK- } \\
565 \mathrm{~F} 18 \mathrm{~s}- \\
\text { EUK- } \\
1134-\mathrm{R}- \\
\text { UNonMet }\end{array}$} & \multirow[t]{3}{*}{454} \\
\hline EtangVallees SaintRobert & & & & & \\
\hline Garbard & & & & & \\
\hline FAS3 FAS4 & Kammerlander et al. (2015) & Alps & $\begin{array}{l}>0.65 \\
\mu \mathrm{m}\end{array}$ & $\begin{array}{l}\text { TAReukV } \\
\text { 4F- } \\
\text { TAReukR } \\
\text { EV3 }\end{array}$ & 454 \\
\hline HL5 HL15 & & Himalaya & $\begin{array}{l}>0.65 \\
\mu \mathrm{m}\end{array}$ & & 454 \\
\hline Aiguebelette & $\begin{array}{l}\text { MG-RAST : } 4703954.3 \text { to } \\
4703966.3\end{array}$ & Alps (France) & $<50 \mu \mathrm{m}$ & $\begin{array}{l}\text { NSF573- } \\
\text { NSR951 }\end{array}$ & 454 \\
\hline Leman & $\begin{array}{l}\text { MG-RAST : } 4703954.3 \text { to } \\
4703966.3\end{array}$ & Alps (France) & $\begin{array}{l}0.2-50 \\
\mu \mathrm{m}\end{array}$ & $\begin{array}{l}\text { NSF573- } \\
\text { NSR951 }\end{array}$ & 454 \\
\hline $\begin{array}{l}\text { Vichy, Aydat, Eguzon, } \\
\text { Pavin, Fades, Cournon, } \\
\text { Grangent, RocheMoines }\end{array}$ & $\begin{array}{l}\text { MG-RAST : } 4703954.3 \text { to } \\
4703966.3\end{array}$ & $\begin{array}{l}\text { Massif } \\
\text { central } \\
\text { (France) }\end{array}$ & $\begin{array}{l}0.2-50 \\
\mu \mathrm{m}\end{array}$ & $\begin{array}{l}515 \mathrm{~F}- \\
951 \mathrm{R}\end{array}$ & MiSEQ \\
\hline Rivers and brooks & & & & & \\
\hline RiverA and RiverB & Bricheux et al. (2013) & France & Biofilm & $\begin{array}{l}528 \mathrm{FE}- \\
1193 \mathrm{E}\end{array}$ & 454 \\
\hline SaintAnneBrook & $\begin{array}{l}\text { Simon et al. (2014) and Simon } \\
\text { et al (2015) }\end{array}$ & $\begin{array}{l}\text { Chevreuse } \\
\text { Valley } \\
\text { (France) }\end{array}$ & $\begin{array}{l}0.2-5 \\
\mu \mathrm{m}\end{array}$ & $\begin{array}{l}565 \mathrm{~F}- \\
1134 \mathrm{R}\end{array}$ & 454 \\
\hline
\end{tabular}




\begin{tabular}{|c|c|c|c|c|c|}
\hline Morcille & $\begin{array}{l}\text { MG-RAST : } 4703954.3 \text { to } \\
4703966.3\end{array}$ & France & Biofilm & $\begin{array}{l}\text { NSF573- } \\
\text { NSR951 }\end{array}$ & 454 \\
\hline & $\begin{array}{l}\text { External references: saline } \\
\text { environments and/or DNA } \\
\text { amplifying by specific primers }\end{array}$ & & & & \\
\hline $\begin{array}{l}\text { Ngallou : hypersaline } \\
\text { ponds }\end{array}$ & Roux et al. (2016) & & & $\begin{array}{l}\text { NSF573- } \\
\text { NSR951 }\end{array}$ & 454 \\
\hline $\begin{array}{l}\text { Blanes Naples Oslo } \\
\text { Roscoff Varna }\end{array}$ & Logares et al. (2014) & & & V4 & 454 \\
\hline Saline lakes & Wang et al. (2014) & & & $\begin{array}{l}\text { A-528F } \\
\text { B-1055R }\end{array}$ & 454 \\
\hline Arctic Ocean & Estelle Kilias et al. (2014) & & & $\begin{array}{l}528 \mathrm{~F}- \\
1055 \mathrm{R}\end{array}$ & 454 \\
\hline Coastal & Bachy et al. (2013) & & & $\begin{array}{l}\text { Ciliates } \\
\text { Tin454- } \\
18 \text { SFw - } \\
\text { Tin454- } \\
\text { 18SRev }\end{array}$ & 454 \\
\hline
\end{tabular}

1

2

3

4

5

6 Table 1: High throughput sequencing (HTS) data used in this analysis 


\section{Table 5(on next page)}

Richness of main taxonomic groups of fungi in freshwater ecosystem 


\begin{tabular}{|l|ccccc|}
\hline & S.obs & S.chao1 & se.chao1 & S.ACE & se.ACE \\
\hline Freshwater & & & & & \\
Fungi & 25771 & 25713 & 61 & 25741 & 69 \\
Ascomycota & 3339 & 3339 & 1 & 3350 & 26 \\
Basidiomycota & 4061 & 4061 & $<1$ & 4063 & 27 \\
Cryptomycota & 9559 & 9559 & $<1$ & 9562 & 41 \\
Chytridiomycota & 3927 & 3927 & $<1$ & 3932 & 28 \\
& & & & & \\
Lakes & & & & & \\
Fungi & & & & & \\
Ascomycota & 17026 & 17419 & 27 & 18057 & 62 \\
Basidiomycota & 2920 & 2962 & 8 & 3044 & 25 \\
Cryptomycota & 2142 & 2153 & 4 & 2188 & 21 \\
Chytridiomycota & 4723 & 5229 & 40 & 5619 & 37 \\
& 3002 & 3035 & 7 & 3122 & 26 \\
Rivers & & & & & \\
Fungi & & & & & \\
Ascomycota & & & & & \\
Basidiomycota & 12453 & 12757 & 23 & 13279 & 48 \\
Cryptomycota & 1009 & 1191 & 26 & 1317 & 20 \\
Chytridiomycota & 2212 & 2228 & 5 & 2282 & 19 \\
\hline & 6891 & 7005 & 14 & 7219 & 36 \\
& 1323 & 1360 & 8 & 1433 & 16 \\
\hline
\end{tabular}

1

2

3

4

5

6 Table 2: Richness of main taxonomic groups of fungi in freshwater ecosystem 